This is a preprint (pre peer-review) version of a paper accepted in its definitive form by the International Journal of Retail and Distribution Management, () Emerald Group Publishing Ltd, http://www.emeraldinsight.com and has been posted by permission of Emerald Group Publishing Ltd for personal use, not for redistribution. The article will be published in the International Journal of Retail and Distribution Management, Volume 31, Issue 3: 153-163 (2003). The definitive version of the paper can be accessed from:

http://www.emeraldinsight.com/Insight/ViewContentServlet?Filename=Published/EmeraldFullTextArticle/Articles/0890310303.html

\title{
Interviews of Deshopping Behaviour: an Analysis of Theory of Planned Behaviour
}

\author{
Tamira King and Charles Dennis \\ Brunel University, Uxbridge, Middlesex, UB8 3PH \\ Tel: 01895274000 Ext:5333 Fax: 01895303149 \\ Email:Tamira.king@brunel.ac.uk
}

Keywords: deshopping; retail borrowing; consumer fraud; retailer return policies.

\author{
Abstract \\ Research reveals alarming results on the prevalence of the dishonest consumer \\ behaviour known as deshopping. Deshopping is the \\ "deliberate return of goods for reasons other than actual faults in the product, \\ in its pure form premeditated prior to and during the consumption \\ experience." \\ (Schmidt et al., 1999 p.2)
}

In effect this means buying something with no intention of keeping it (Schmidt et al., 1999). The authors consider the implications of deshopping and retailers' prevention of deshopping, exploring the research undertaken to date and the methodology for further research.

\section{Introduction and Background}

The emphasis on the importance of the self-image of products consumed and their psychological significance (Warde, 1994) has lead to extensive pressure and risk being associated with the purchasing decision and the later consumption of a product, (Mitchell and McGoldrick, 1996). In order to gain competitive advantage, retailers attempt to reduce this risk by introducing the opportunity to return goods for a refund (Mitchell and McGoldrick, 1996; Schmidt et al, 1999 ). Return goods policies are a method which allows the customer to defer their purchasing decision until after they gain some experience with the goods. As a result customers have learned that they can counteract their purchasing decision by returning the purchase (King, 2001). Nevertheless the policy of returns within time limits is open to abuse by deshoppers. The return policies of retailers are facilitating the practices of deshopping and retail borrowing. Evidence in previous research (King, 1999; King 2001; Schmidt et al., 1999) highlighted the prevalence of deshopping.

\section{Theory of planned behaviour (TPB)}

The authors have utilised the theory of planned behaviour (TPB) (Aijzen 1985, 1991), which attempts to explain variables in human behaviour. This method has been utilised in other studies to understand the mechanism of undesirable human behaviour such as quitting cigarette smoking (Devries \& Backbier 1994 ), and condom use and safe sex (Boldero et al, 1992). TPB was derived from the theory of reasoned action (TRA). The difference is that TPB incorporates the additional dimension of Perceived Behavioural Control, (PBC) (East, 1997). PBC may therefore be relevant for deshopping analysis, where the aim is to control an undesirable behaviour. If PBC correlates with the behaviour, the research should be able to identify the mechanisms that will reduce and control the behaviour. 
Figure 1 Model

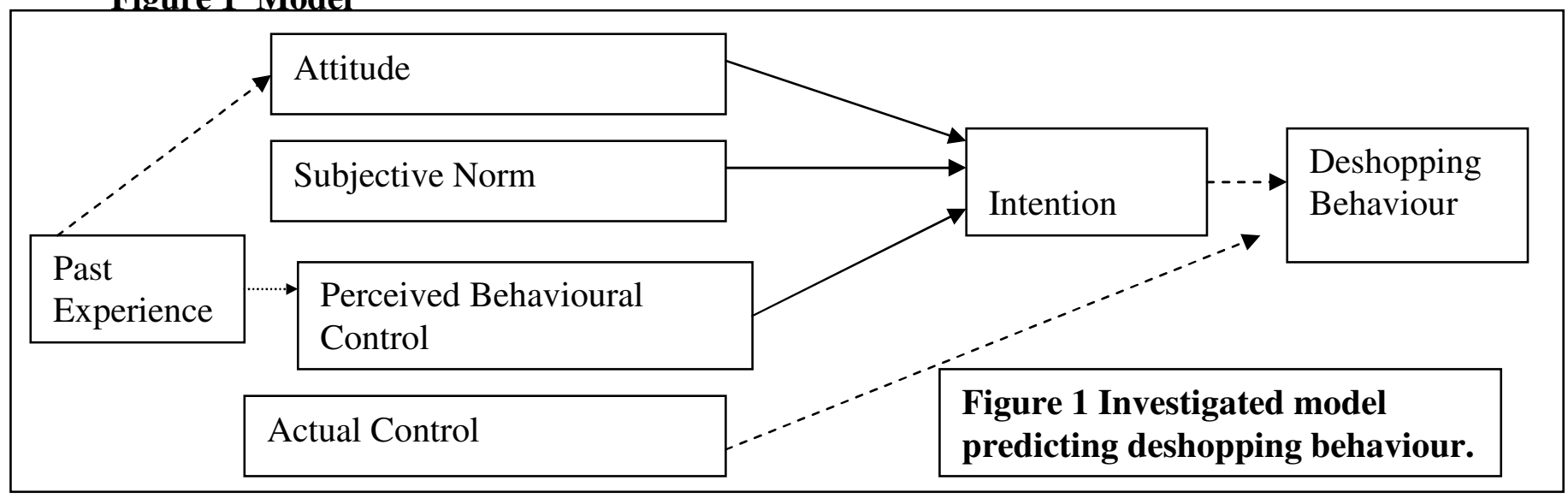

\section{Development of Model (Fig 1)}

According to the Theory of Planned Behaviour, intention to perform a behaviour is influenced by four major dimensions: attitude, subjective norm, perceived behavioural control and actual control. A person's attitude towards a behaviour represents evaluation of the behaviour and its outcomes. The subjective norm concerns the extent to which other people important to a respondent approve or disapprove of the behaviour. Perceived behavioural control refers to the ease or difficulty of performing the behaviour. Actual control concerns the tools respondents use to ensure their control during the behaviour. (Ajzen, 1985;1991).In this study we have considered this simple model illustrated in Figure 1. In this model, these five areas have been investigated, with the belief that they will allow the researcher to predict the deshopping behaviour. 1. Attitude towards deshopping will significantly predict deshopping behaviour; 2 Shoppers' perceptions of the extent to which others important to the respondents approve of deshopping (subjective norm) will significantly predict deshopping behaviour; 3 Shoppers' perceptions of the ease of carrying out deshopping (perceived behavioural control) will significantly predict deshopping behaviour. 4. The shoppers past experience of deshopping and returns will affect their confidence and perceived ability to partake in the behaviour, (perceived behavioural control). 5. Actual control. This is predicted to reduce the behaviour e.g. if a person was caught partaking the behaviour then they are less likely to engage in the behaviour again. In addition it has emerged during this study that past experience may influence attitude.

\section{Data Collection}

Five hundred and twenty eight questionnaires were completed. The questionnaire methodology and results are reported elsewhere, the paths indicated by solid lines in figure 1 were identified as significant to deshopping. From the results deshoppers were identified on a scale of partial to real deshoppers. Partial deshoppers represented $425(80 \%)$ of total sample total. Real deshoppers (the more extreme end of the scale were represented by $266(50 \%)$ of the total sample.

\section{Interviews with Deshoppers.}

All deshoppers identified (partial \& real) in the 'deshopping' questionnaires were eligible for interview. All those who had given address and telephone numbers were contacted by mail, to ask whether they would participate in the interview. This was followed up by a telephone call asking to arrange a convenient date for the interview. 


\section{Limitations}

Many of the telephone numbers did not exist, many letters were returned to sender, and many people were not contactable or unwilling to partake further. Several interviewees did not turn up for the interviews. Nine semi-structured interviews were conducted and audio-recorded.

\section{Methodology}

The quantative results demonstrated that the paths indicated by solid lines in model 1 were significant to deshopping. The interviews have been used in conjunction with the data to allow a deeper understanding of the areas highlighted. Wells (1994) suggests that interviews may also be a means to validate the findings from the questionnaire. They aid the process of gathering reliable and valid data which are relevant to the research questions and objectives (Emory and Cooper, 1991).

Face to face interviews enabled the researcher to work closer with respondents. The interviews were aimed at gaining an understanding of how the interviewee constructs the meaning and significance of the situation. To achieve these insights the researcher has to understand the other person's views but also assists them exploring their own beliefs, (Easterby-Smith et al., 1993). The interviews were informal. They were used these to explore the area in-depth. There was no predetermined list of questions to work through, although the researcher had a clear idea about the aspects to explore. The interviewee was given the opportunity to talk freely about events, behaviour and beliefs in relation to the topic area. (Saunders et al., 1997, p.231). The interaction is non-directive as the interviewee's perceptions guide the interviewer (Ibid). Healey and Rawlinson (1994 p.130) suggest a combination of styles may be used within one interview. At times the interview becomes a respondent interview where the interviewer directs and the interviewee responds, when the interviewer wants the interviewee to expand on an area of interest, which results in rich data. This is important in our case where an interviewer is concerned with understanding the meaning which respondents ascribe to a various phenomena, (Saunders et al., 1997).

\section{Interview Topics}

The interviewer tried to guide (when necessary) the interviewees to discuss the topics below:

The interviews tried to identify their general attitude towards shopping and their shopping behaviour to break the ice and ease into the more sensitive areas.

Q. How often do you go shopping?

Q. How do you feel when returning garments?

The interviewees were given two example scenarios to move focus to deshopping behaviour and assess their attitude.

Scenario 1. Purchasing a dress for special occasion e.g. Wedding and returning after fulfilled purpose

Scenario 2. Purchasing a garments e.g. a top purchased for a Saturday night worn and then damaged so it can be returned

The interviewees were asked if they had ever experienced either scenario to provide evidence of deshopping, and level of deshopping

Q. Can you give examples of products/garments that you have returned to retailers or taken back recently?

Why were taken back? How old product garment? How did you feel? How often do you return garments?

Exploration of control beliefs

What makes an interviewee comfortable/ embarrassed/ confident? 
Are you aware of retailer's policies/consumer law?

Exploration of past experience

What is perception of past experience? How does this affect your likelihood to partake in behaviour?

Have you ever felt uncomfortable during return? Do you have a plan

Investigate their opinion of retailer role

What part does the retailer play?

Exploration of subjective norm

How do people/friends/parents view the scenario? Does this affect whether you partake in behaviour?

Exploration of Intention

Do you deshop with 'intention' at purchasing point?

Do they return garment knowing it is not genuine return (intentionally)?

Have they deshopped since completing the questionnaire?

\section{Interview Results}

For purposes of anonymity interviewee names have been altered. Interviews have been clustered into the four main elements of the deshopping model investigated.

\section{Deshopping Examples}

Interviewee 1. Liz.

$\diamond$ Liz describes a top she purchased recently from Gap, wore it and did not feel good in the top, so is going take it back.

$\diamond$ Dining table $£ 1,200$ pounds. As Liz entertains a lot of people with children, after 6 months the table looked worn. 'I complained and took it back and bought a more suitable table. I really chose a table that was not practical.'

$\diamond$ Liz's Engagement gift list from M\&S was delivered twice, an estimated $£ 600$ worth of products 'all in boxes and brand new' 'I took it all back,' for a full refund.

\section{Subjective Norm}

Influence by friends

$\diamond$ My friends wrote a letter complaining about holiday, so I did and we are expecting a discount next holiday.

$\diamond \mathrm{I}$ bought a Burberry's bag, with my friend she told me recently that she had taken her bag back because the corners worn, and they gave her a new bag. Now I know that, I am going to take mine back.

Fear of Fiancé's opinion of behaviour

$\diamond$ Being just engaged I did not know what my fiancé's view would be when I suggested returning gift list. I thought he would disapprove. When I suggested it he said it was 'stealing,' but I persuaded him it would be 'ok'.

Fiancé's fear of other people's perception of behaviour

$\diamond$ "He told me never to tell anyone that story. But I don't regret it."

Concern for parents opinion of behaviour

$\diamond$ Also her mum would not approve or return garment if aware that Liz had worn it, her mum would say 'good luck to you if you can get away with it' but would not do it for her. Liz felt slightly guilty.

$\diamond$ Her father is horrified at the piles of garments she returns.

\section{Past experience}

$\diamond$ Liz has never been caught deshopping, and if she perceived that there was a chance of being caught she would 'not have the balls to do it'

$\diamond \mathrm{Liz}$ has rarely experienced a manager being called, especially because she has only had the 'garment for a week and has receipt'. 


\section{Control Belief}

$\diamond \mathrm{Liz}$ always checks that there are no marks on garments for evidence and it 'looks genuine'.

$\diamond \mathrm{Liz}$ ensures that all her receipts are kept safely. 'Every night she empties her bulging purse and shopping bags and files receipts'. She also checks the receipts with her credit card bills at a later date.

$\diamond \mathrm{Liz}$ will pick a specific till that does not look threatening.

$\diamond \mathrm{Liz}$ will try to busy herself during returns process, with the children, a phone call or pretend she is in a hurry so that she is not available for questioning by staff.

$\diamond$ Liz plans her response in advance of returning the garment that she has worn to Gap, 'it was purchased for a cousin or niece and they do not want it.' Introducing a 'niece' allows Liz to disassociate herself from process, in case the legitimacy of return is questioned.

$\diamond \mathrm{Liz}$ believes that if you say you are an account customer returns are easier, as you are questioned less.

$\diamond$ Liz's legal knowledge is limited but Liz states "its my word against theirs," if they said there were marks on a garment I would say that I had walked around in top for 10 minutes.

$\diamond$ Liz's understanding of return policy is clear as stores 'tell me the return policy when I purchase products'.

$\diamond \mathrm{Liz}$ took so much back she became familiar with the employees so she alternated returns between Brent Cross to Watford. So that they "would not recognise me"

\section{Intention}

$\diamond$ For a special occasion coming up I need a pashmina, just to literally wear to walk in and walk out, with a strapless. For a hundred quid I could get one to return from John Lewis, or Fenwicks. ' I would cut off the tag and receipt and keep it in the bag, for return.'

$\diamond \mathrm{Liz}$ states that this is never intentional at time of purchase. She likes the garments at time of purchase, but is a bad shopper, and they do not look good when worn out, so they have to be returned when she changes her mind.

\section{Perceived Behavioural Control}

$\diamond$ Liz feels that over the last 5-10 years returning has got a lot easier

\section{Attitude}

$\diamond$ "Give it a go. The worst that can happen is they will not take it back. They cannot arrest you!" Liz believes the main consequence of deshopping to be embarrassment.

\section{Deshopping Example}

\section{Interviewee 2.Karen.}

$\diamond$ Karen has worn something, then decided that she didn't like it so returned it.

"I have done it once because I had worn it and did not like it that much. It was top from Pilot. I wore it 2-3 times then picked seam, as a reason to go and

\section{Past Experience} give it back. I was excited to get my money back and get rid of top"

$\diamond$ Prior to return Karen felt apprehensive, and nervous that they would not believe her.

"The feeling has put me off it will be just the one time I am going to get caught

\section{Subjective norm} out and I feel guilty that I ruined the top to get money back."

$\diamond$ Karen is keen to get her parents approval for returns and if something is wrong with a garment she will ask her mum before she takes it back. 
$\diamond$ Deshopping is popular with Karen's friends. Karen has not told her friends as she does not feel good about her past deshopping experience, and would not recommend it

\section{Control belief}

$\diamond$ Karen understands the return policy, but not the legal details.

$\diamond$ At point of return Karen stated that she had bought the top for her sister and she didn't like it as it was too small and wanted a refund. This allows her to detach from responsibility at point of return.

$\diamond$ When deliberately damaging the garment 'the seam looks more realistic than taking scissors to it"

\section{Attitude}

$\diamond$ Karen thinks this behaviour depends on the individual situation

Perceived Behavioural Control

$\diamond$ Karen did not find deshopping difficult, but unpleasant as she felt guilty

\section{Intention}

$\diamond$ Karen's deshopping experience was not premeditated at time of purchase or purchased intentionally for a return, but for a Saturday night. She states that she

'Needed something to wear, it was getting late went in and bought it but didn't like it very much, wore it, and then took it back. Read receipt and knew she could take it back soon'

\section{Deshopping Examples}

\section{Interviewee 3. Heather}

$\diamond$ Heather explaines how she wore a dress for a party then returned it. "I wanted a dress, but mum wouldn't lend me the money, I liked the dress so I wore it and then came back next morning and took it back with my friends."

$\diamond$ Heather bought a top for a leaving party, then returned it

\section{Subjective norm}

$\diamond$ Heather feels that she is not influenced by her mum, only her friends.

$\diamond$ Heather got the idea, from her best friend. She went shopping with her when she did it.

$\diamond$ Heather explains how she purchased trousers with her mum, and her mum took them back after she had worn them.

"mum is up to date with all tricks, I learn how to argue from her. I don't always tell her as sometimes she will give me a lecture, but she thinks some of my friends do it all the time and if I only do it a couple of times it won't make

\section{Control beliefs} a lot of difference."

$\diamond$ Heather is not concerned with knowing her legal rights or return policies. $\diamond$ Heather feels more comfortable with certain retailers e.g. Miss Selfridge.

$\diamond \mathrm{I}$ am better when a friend comes in with me as they are very strong willed, and help me argue.

$\diamond$ Before returning garments Heather ensures that there is no queue to save embarrassment, she also considers what the sales assistant looks like.

$\diamond$ Heather, 'keeps all receipts in bag for couple of weeks after purchase.'

\section{Attitude}

\& "I knew what I was doing was wrong but really wanted to wear dress and really wanted to go to party." 
$\diamond$ Heather blames her behaviour on financial difficulties. She only deshops,

"in desperate situations, it is not a regular habit, but if needs be that's what I do,"

Past Experience

$\diamond \mathrm{I}$ was nervous before the return but did not have a plan as,

"I was confident it would work as I had done it before." I have never had a problem so far and I find it relatively easy. If it was difficult would be less likely to work as I would be more tense."

$\diamond$ 'My best friend Chloe had a receipt when she made a hole in the left side of dress. She was pissed off when the shop wouldn't take it back. She still shops and takes back in there as we do not see the same people again.'

\section{Intention}

$\diamond$ "If money situation is not that good, and I only want it for one night, it is wrong but it is the only way. It's not something I am planning to do."

$\diamond \mathrm{I}$ have done it about three times since completing the questionnaire, and a bit before then as well.

\section{Deshopping Example}

\section{Interview 4.Linda}

$\diamond \quad$ "I bought a top in Jane Norman, as I needed the money so I took it back. I was careful with it cause I new I would take it back."

$\diamond$ Linda says she has deshopped about six times and she would return clothes "whenever she needs to do it"

'A skirt hem the thread was loose so I pulled that, and said it had just come undone, that was from Tammy so it was $£ 17$ '

$\diamond$ Linda explains that she

"tucks the labels in tops when I wear them and if I can see a bit of plastic then I wear a cardigan with it."

\section{Subjective Norm}

$\diamond$ Linda's friends deshop. "If my friends didn't do it I wouldn't have came up with the idea, I only started doing it when I changed school."

$\diamond$ Linda states that her mum thinks she has "done it once, she was alright but told me not to do it again and if I would rather have the money then I should not get the top."

$\diamond$ Linda observed a friend for the first time, and when she saw how easy it was she thought 'I can do this'

\section{Past Experience}

$\diamond$ Linda or her friends have never encountered any problems when deshopping, and the sales person never argues.

$\diamond$ She states that if she had difficulty she would be less confident to take things back next time.

$\diamond$ If she was refused a refund she would be annoyed as she could not wear the top again as it had a hole in

$\diamond$ Linda explains that if her friends have taken something back to a store and she can see it was easy, then she would try that shop.

\section{Control Beliefs}

$\diamond$ Linda shops where she knows the return policy. She ensures that she only keeps her tops for little time when she wants to take them back so that there is no problem.

$\diamond$ Her friends ensure that they do not do it at the same time as it would look too obvious.

$\diamond$ Linda takes her friends in with her when returning as they give her more confidence and they make the sales girl feel under pressure. 
$\diamond$ Linda is not familiar with the law or return policies

$\diamond$ Linda will deshop in the same store, but not immediately.

$\diamond$ Linda is careful when wearing garments that she is going to return, in case someone spills something on her.

\section{Deshopping Example}

\section{Interviewee 5. Hetty}

$\diamond$ Hetty describes one occasion in Warehouse, with a $£ 45$ top that she wore for a night out and then did not need it anymore. It was not premeditated at time of purchase.

Perceived behavioural control.

\& Hetty perceives deshopping as 'Quite easy' because 'customers have so many rights.'

$\diamond$ You can take nearly take anything back, and its not as scary as you think it should be really.

\section{Control beliefs}

$\diamond$ Hetty will also disassociate herself from blame by saying 'her sister doesn't like it or it doesn't fit her' so she is not playing a role in the process.

$\diamond$ Hetty believed that legally retailers

"have to take almost all things back by law...they basically just have to take it back."

$\diamond$ Hetty says,

"My Sister was manager of Knickerbox so she had to deal with people so you pick up little things. A shop cannot accuse you of lying unless it's really obvious."

\section{Subjective norm}

$\diamond$ Hetty's mum knows she has done it but her father does not know.

$\diamond$ She explains how her elder sisters of (28 and 24), damage clothes and 'snap heels off of shoes and stuff.'

$\diamond$ Hetty's mother does not approve but says, if you want to you can, but think about what you are going to say before you walk in there

\section{Intention}

$\diamond$ Deshopping is an option if she really needed the money back or really did not like her purchase.

\section{Past Experience}

$\diamond$ Sisters have always got away with it so that influences her.

$\diamond$ From my experience a lot of the time they don $t$ ask questions, when my friends do it all the time

$\diamond \mathrm{I}$ have seen my sister have a row with a shop assistant

"I thought it was funny so I left the shop, in Brent Cross with her boyfriend. She ended up winning and getting an exchange, I bet she felt great after wards."

\section{Attitude}

$\diamond \quad$ "when it comes down to it then its only taking it back to the shop."

\section{Deshopping Example 1}

\section{Interviewee 6.Lilly}

$\diamond$ Lilly describes returning a $£ 70-80$ pair of trousers to Morgan, having unpicked the studs down the side seam. Lilly's trousers had shrunk, but she knew that if they were faulty then she could return them.

$\diamond$ Lilly recalls wearing a pair of Jeans and returning them after they had been worn. $\diamond$ Lilly recalls returning shoes at 16 , (now 25) having worn them for 8-9 months and being given a selection of shoes to replace them with. 
s'I always take CD's back, record them then return them...always. I've done that loads. I wouldn't think twice. I used to do it every week,'

$\diamond$ Lilly describes getting a free video with a $£ 2.99$ book and then returning the video to HMV for a $£ 15$ refund

\section{Control belief}

$\diamond$ Lilly was concerned when giving her contact details to the sales assistant so gave a false address but a correct mobile so she could be contacted for new stock.

$\diamond$ Lilly took her bank statement to prove where the garment was purchased.

$\diamond$ Lilly is aware of returns policies

$\diamond$ Certain retailers make Lilly feel more comfortable as 'M\&S is easier to return than Morgan'. Lilly would not return CD's to Our Price as their CD's are wrapped up

\section{Subjective norm}

$\diamond$ Lilly is too embarrassed to tell her friends about these incidents. However, feels that she is influenced by them because

'if they can do it, why can't I?'

$\diamond$ Lilly felt her mother would not be bothered but would be concerned is Lilly continued doing things like that.

\section{Past Experience}

$\diamond$ Lilly describes her experience as quick, and she could easily do it again by unpicking stitching.

$\diamond$ Lilly tried to return shoes she had had for about a year. The manager said he would send them for repair, not replace them. This has not affected her perception of the ease of deshopping.

$\diamond$ With CD's “ I literally used to do it every week, I have never had a bad experience, it's never a problem, and I never think about it"

\section{Attitude}

$\diamond$ Lilly is confident when returning genuine garments/products but 'feels bad when she's returning stuff that she should not be'.

\section{Deshopping Example}

\section{Interviewee 7. Gail}

$\diamond$ Gail purchased a heated hair Tong from Boots, Gail used the tongs for two weeks, and the tongs did not heat up enough and straighten the hair to the look she required, so returned them.

\section{Past experience}

$\diamond$ When returning Gail feels that staff look suspiciously at customers which makes her feel guilty.

\section{Control belief}

$\diamond$ Gail always keep receipts about a month, just in case.

$\diamond$ Gail asked her mother to return the tongs for her and refund them.

\section{Subjective norm}

$\diamond$ Gails mother returned the tongs but insisted that she would not do it again. She states that if her mother had refused to return the tongs Gail would have kept them.

$\diamond$ Gails friends told her she 'was a cheapskate' when she repeated the story.

\section{Attitude}

$\diamond$ Although Gail insists that she would not wear a top and then return it. If she purchased a garment and it was a lot of money taking it back after is an option, and cannot be ruled out.

$\diamond$ Gail explains that this is acceptable when not done with intention at time of purchase. 
$\diamond$ Gail would 'Never rule it out, is always an option, though I could get money back' Perceived behavioural control

$\diamond$ Gail believes that the consequence is not getting a return or exchange as the police would not be involved as it is not shoplifting or stealing 'its just misrepresentation of facts.'

\section{Deshopping Experience}

\section{Interview 8. Tara}

s I bought a stunning dress and wrap for my friends engagement, I really enjoyed wearing it, and bought it on the Friday and I took it back straight after the weekend.

$\diamond$ I have had clothes for ages got bored of them so I unpick a seam and then take them back.

$\diamond$ I can change my outfits regularly, and adopt all the latest seasons styles without any financial repercussions.

\section{Past Experience}

$\diamond \mathrm{I}$ do this all the time, and never have any problem. It is so easy.

$\diamond \mathrm{I}$ have done it at loads of different shops.

\section{Control Belief}

$\diamond$ You don't need to keep the receipts, without a receipt it can be more of a challenge $\diamond \mathrm{I}$ know what I can do and can't.

$\diamond$ Never keep the tags on garments you don't need to.

$\diamond$ Tara has worked in high street retailer so is aware of return policies

$\diamond$ Tara does not think it is necessary to know your legal rights 'you just have to hold your ground.'

\section{Subjective norm}

$\diamond \mathrm{I}$ often have to hide my shopping bags from my parents, and I always lie about the cost of my purchases' as they would go mad, if they knew how much I spent.

$\diamond$ My friends know that I do it I think my mum knows as well.

$\diamond$ I never discuss clothes or shopping with my dad.

\section{Perceived Behavioural Control}

$\diamond \mathrm{I}$ have had managers called over before, but I put on my mask which believes I am right and pretends that I have not done anything wrong and I could argue all day till I get my money back.

$\diamond$ Its my word against theirs.

\section{Attitude}

$\diamond$ This is a real buzz and seeing as the retailers are ripping you off I do not feel bad at all. After all they make it so easy, what do they expect?

\section{Deshopping Experience}

\section{Interview 9. Paula}

$\diamond \mathrm{I}$ had worn trousers for Xmas day and for new year and enjoyed wearing them and them took them back.

\section{Past Experience}

$\diamond$ I have heard of my daughters friends (she is 28) doing this, and they never have any problems, 'so I though if they can all do it then why can't I?'

\section{Control Belief}

$\diamond$ When I am in the wheelchair people feel sorry for me and never ask me questions when returning.

$\diamond \mathrm{I}$ did not keep my receipt as I did not need to, especially at 'Marks.'

\section{Subjective norm}

$\diamond \mathrm{I}$ had to go shopping with my husband because of the chair, he was quite happy with us returning them as long as we got our money back, why not? 
$\diamond \mathrm{I}$ have told friends, and my daughters friends who thought it was great. I am not embarrassed because but it shows the retailer up not me.

\section{Perceived Behavioural Control}

$\diamond$ It was easy they asked no questions at all.

\section{Attitude}

$\diamond \mathrm{I}$ really would not like to buy something that had been worn, but I believe that if there are no consequences, and every else is doing is, then I do not have a problem with it.

\section{Conclusion}

$\diamond$ Intention. The questionnaire highlights that 'intention' to deshop a garment is not always evident at the point of purchase. The deliberate return of a garment may not be pre-meditated from the outset, but it is intentional at point of return.

$\diamond$ Perceived Behavioural Control. This demonstrates the large element of control that the deshopper perceives they have over the deshopping process and its successful outcome. The interviews highlight the perceived 'ease' at which they carry out deshopping. If this perception of control could be altered e.g. by tightened return policies -the behaviour could be reduced.

$\diamond$ Subjective Norm. The findings support questionnaire results that deshoppers are concerned with opinions of people who are important to them. The interviews highlight that the respondents are influenced by people (sisters, friends, parents) in a negative way as well as in a constructive and beneficial way. With consumer education, deshopping should become less acceptable and the deshopper should be more likely to discontinue the behaviour.

$\diamond$ Past Experience. Deshoppers have not encountered serious problems or punishment as a result of fraudulent returns. The deshoppers have witnessed friends having arguments with retailers, and 'winning.' They also consider that the worst a past experience can be is being refused a return and therefore having to keep the garment. This past experience is influential in their perception of deshopping being easy, and contributes to the attitude that they may as well try it because they have nothing to lose.

Their successful previous dehsopping experiences enable the consumer to have a deeper understanding of the return process thus which enhancing their knowledge and confidence for the next time. This enables deshoppers to perceive that they themselves have control over many areas.

s Attitude. Attitude is closely associated with deshopping as is $\mathrm{SN}$ and PBC. Retailers can address PBC readily by imposing strict returns procedures, and SN by introducing an education programme. There is usually no obvious way to affect attitude except by advertising, which has often been of minimal effectiveness in previous 'negative behaviour' campaigns e.g. drink driving. Significantly our results demonstrate that attitude can be altered by changing past experience. As retailers make returning procedures 'easy' the deshoppers develop a more positive attitude to deshopping. The results show that if making deshopping hard deshoppers could alter attitudes. To make returns hard, retailers could e.g. introduce returns logging programs. This tracing device would make returns appear more difficult and this would affect perceived behavioural control, actual control and attitude. 
$\diamond$ Actual Control. From the previous structured questionnaires it was concluded that deshoppers would be less likely to deshop if they perceived it to be difficult. The in depth interviews indicate that just by very rarely refusing a refund, retailers are not doing enough to make deshopping difficult.

This is because at present, when the deshoppers encounter a refusal of return, it is not recollected as a bad experience. So this is not deterring them from partaking in the behaviour again. The interviews particularly demonstrate that if this experience had led to severe embarrassment or involved the police or criminal proceedings it would change the deshoppers actual control and attitude.

The interviews also support pervious research that deshoppers differentiate between mass market and independent retailers, (Schmidt et al., 1999). They blame deshopping on altruistic and financial needs. The retailer is often perceived as playing a role in deshopping by being expensive and encouraging returns. There are also some deshoppers who demonstrate traits of compulsive consumption. These elements will be explored elsewhere.

\section{Continued work in process}

The data collected on the correlation of subjective norm and $\mathrm{PBC}$ and deshopping behaviour in the questionnaire and interview will enable the researcher to identify mechanisms that could be put in place that would reduce and control the behaviour.

By studying the respondents' attitude to the behaviour and past experience we can obtain their evaluation toward the behaviour to see if this affects the possibility of partaking and performing deshopping. Finally by addressing belief based measures it should be possible to gain insight into the underlying cognitive foundation, and explore why people hold certain attitudes, subjective norms, and perceptions of behavioural control.

\section{References}

Ajzen I (1985) 'From Intention to action: a theory of planned behaviour', in Kuhl J and Beckman J (eds.), Action Control: From Cognitions to Behaviours, New York, Springer.

Ajzen I (1991) 'The Theory of Planned Behaviour', Organisational Behaviours and Human Decision Processes, 50:179-211

Boldero J, Moore S, Rosenthal D,(1992) Intentions Context and Safe Sex. Journal of Applied Social Psychology 22 (17) 1374-96

Breakwell G M, Hammond S and Fife-Schaw C (2000) Research Methods In Psychology, $2^{\text {nd }}$ edition, London, Sage.

Devries, H \& Backbier (1994) Self Efficiency As An Important Determinant Of Quitting Among Pregnant Women Who Smoke:The PHI Pattern, Preventative Medicine 23(2)167-74

East R (1997) Consumer Behaviour, Hemel Hempstead, Prentice Hall (and accompanying 'NEWACT' and 'README PC Files).

Elliot,R. (1997) Symbolic Meaning and Post-Modern Culture, In: Bromlie,D. et al (Eds) Rethinking Marketing, Sage London.

King T (1999) To Examine The Phenomenon of Deshopping and Retail Policies Preventing Deshopping. Unpublished dissertation for Msc at Manchester Metropolitan University King T (2001) The Phenomenon Of Deshopping And Retail Policies Preventing Deshopping. $11^{\text {th }}$ International Conference on Research in the Distributive Trades. EIM/Tilburg University/Erasmus University/TIAS Business School 
Mitchell \& McGoldrick (1996) Consumers' Risk Reduction Strategies : A Review And Synthesis. The International Review Of Retail, Distribution, And Consumer Research. 6(1) pp. 1-33.

Schmidt R, Sturrock F, Ward P, and Lea-Greenwood G (1999) 'Deshopping The Art of Illicit Consumption,' The International Journal of Retail and Distribution

Management. 27 (8) 209-301

Warde, A (1994) Consumption, Identity-formation, and Uncertainty. Sociology. 28(4) pp.877-898.

Ward, P \& Sturrock,F (1998) "She Knows What She Wants...". Towards A Female Consumption Risk Reduction Strategy Framework, Marketing Intelligence And Planning, 16,(5) pp.327-336

Ward,P \& Sturrock, F, \& Schmidt,R.A. (1998), To Shop or Deshop- That Is The Question. Proceeding Academy Of Marketing Conference, Sheffield 